\title{
Comunicação
}

\section{Desenvolvimento do maracujá doce em Viçosa, Minas Gerais}

\author{
Robson Ribeiro Alves ${ }^{1}$, Luiz Carlos Chamhum Salomão², Dalmo Lopes de Siqueira², \\ Paulo Roberto Cecon ${ }^{2}$, Danielle Fabíola Pereira da Silva ${ }^{3}$
}

\section{RESUMO}

Foram avaliadas as mudanças físicas, químicas e fisiológicas ocorridas durante o desenvolvimento do maracujá doce, da antese até o completo amadurecimento na planta. Os frutos apresentaram formato ligeiramente oblongo, padrão de desenvolvimento sigmoidal simples e padrão climatérico para a respiração. O desenvolvimento do fruto foi dividido em três fases: divisão celular até 4,70 dias após a antese (daa), expansão celular de 4,70 daa até 28,94 daa e maturação, de 28,94 daa a 91 daa. Na primeira fase, há pouco incremento nas dimensões do fruto, altas taxas respiratórias, crescimento acelerado da espessura do pericarpo e coloração do pericarpo verde-claro. Na fase seguinte, há intenso desenvolvimento das dimensões do fruto, ganho acelerado de massa da matéria fresca e coloração do pericarpo verde-intenso. Na terceira fase, há tendência à estabilização das dimensões, desenvolvimento de polpa acentuado, o teor de sólidos solúveis aumenta, os teores de vitamina $\mathrm{C}$ e acidez titulável diminuem. O pico do climatério foi registrado aos 63 daa. No último dia de avaliação, aos 91 daa, a polpa (suco + sementes) representava 24,46\% da massa da matéria fresca total do fruto, o pericarpo respondia por 74,10\% e as sementes isoladas, por 3,14\%.

Palavras-chave: Passiflora alata Curtis, análise de crescimento, ponto de colheita.

\section{ABSTRACT}

\section{Fruit development of sweet passion fruit in Viçosa, Minas Gerais}

The physical, chemical and physiological changes during the development of sweet passion fruit, from anthesis to ripening in the plant, were evaluated. Fruits had a slightly oblong shape, a simple sigmoidal pattern of development and climacteric pattern for respiration. Fruit development was divided into three phases: cell division up to 4.70 days after anthesis (daa); cell expansion from 4.70 daa to 28.94 daa and maturation from 28.94 to 91 daa. In the cell division phase, there is little increase in fruit size, high respiratory rates, rapid growth of the pericarp thickness, and pericarp of clear green color. In the cell expansion phase, there is intense development of the fruit's dimensions, accelerated fresh weight gain and pericarp of intense green color. In the maturation phase, there is a tendency to stabilize dimensions, rapid development of pulp, the soluble solids content increase and vitamin $\mathrm{C}$ and titratable acidity decrease. The climacteric peak was recorded at 63 daa. On the last day of evaluation, at 91 daa, the pulp (juice + seeds) accounted for $24.46 \%$ of total fresh weight of the fruit, the pericarp accounted for $74.10 \%$ and isolated seeds for $3.14 \%$.

Key words: Passiflora alata Curtis, growth analysis, harvest time.

\footnotetext{
Recebido para publicação em 07/12/2011 e aprovado em 17/09/2012.

'Químico, Mestre. Departamento de Fitotecnia, Universidade Federal de Viçosa, Campus Viçosa, Avenida Peter Henry Rolfs, s/n, 36570-000, Viçosa, Minas Gerais, Brasil. robson@ufv.br (autor correspondente).

${ }^{2}$ Engenheiro-Agrônomo, Doutor. Departamento de Fitotecnia, Universidade Federal de Viçosa, Campus Viçosa, Avenida Peter Henry Rolfs, s/n, 36570-000, Viçosa, Minas Gerais, Brasil.1salomao@ufv.br; siqueira@ufv.br; cecon@ufv.br

${ }^{3}$ Engenheira-Agrônoma, Doutora. Departamento de Fitotecnia, Universidade Federal de Viçosa, Campus Viçosa, Avenida Peter Henry Rolfs, s/n, 36570-000, Viçosa, Minas Gerais, Brasil. danieele@ufv.br
} 


\section{INTRODUÇÃO}

O maracujazeiro doce (Passiflora alata Curtis) pertence à família Passifloraceae, ao gênero Passiflora, ao subgênero Granadilla e à série Quadrangulares (Anjos et al., 2005). É uma espécie nativa do Brasil e de ocorrência bastante generalizada, podendo ser encontrado crescendo espontaneamente ou cultivado em todos os estados do País.

A análise do crescimento apresenta-se como técnica válida para estudar as bases fisiológicas da produção e pôr em evidência a influência exercida pelas variáveis ambientais, genéticas e agronômicas (Veras et al., 2000). Essa técnica descreve as condições morfofisiológicas da planta em diferentes intervalos de tempo, entre duas amostragens sucessivas, e permite acompanhar a dinâmica da produção fotossintética avaliada pela acumulação de massa da matéria seca (Salomão et al., 2006).

Neste trabalho foram avaliados o ciclo e as mudanças físicas, químicas e fisiológicas ocorridas durante o desenvolvimento dos frutos do maracujazeiro doce em Viçosa, Minas Gerais.

\section{MATERIAL E MÉTODOS}

O experimento foi conduzido de 11 de julho a 10 de outubro de 2008, em Viçosa, Minas Gerais, situada a 651 m de altitude, $20^{\circ} 45^{\prime} 20^{\prime \prime} \mathrm{S} \mathrm{e} 42^{\circ} 52^{\prime} 40^{\prime \prime} \mathrm{O}$, com clima tipo Cwa, mesotérmico úmido com verões chuvosos e invernos secos. Durante o período experimental, foi registrada forte seca, com precipitação pluvial total de $173,4 \mathrm{~mm}$ e umidade relativa média de $75,4 \%$.

Os frutos foram colhidos de 20 maracujazeiros doces, com cerca de dois anos de idade, conduzidos em ambiente aberto em forma de espaldeira com um fio de arame localizado a $1,80 \mathrm{~m}$ de altura do solo.

Durante o surto principal de florescimento foram marcadas flores no dia da antese. A polinização foi natural. Decorridos sete dias das marcações, foram feitas recontagens das flores marcadas, a fim de determinar o percentual de frutos fixados. A partir de então, foram coletadas, semanalmente, amostras de frutos até o amadurecimento na planta.

Os frutos coletados, num total de 20 por período de amostragem, foram divididos em quatro repetições de cinco frutos cada. Foram avaliadas as características: comprimento, diâmetro e volume do fruto, espessura do pericarpo (na porção mediana do fruto cortado), ângulo hue do pericarpo e a massa do fruto. Após a separação das partes do fruto, foram determinadas as massas do pericarpo e da polpa (incluindo sementes, arilo e suco) e a massa da matéria seca do pericarpo, após secagem em estufa a $70 \pm 5^{\circ} \mathrm{C}$, por $72 \mathrm{~h}$.
Também foram avaliadas as seguintes características químicas: teor de sólidos solúveis (determinado por refratômetro digital), teor de vitamina C (mg ácido ascórbico por $100 \mathrm{~g}$ de suco, determinado pelo método de Tillman [2,6 diclorofenolindofenol (sal sódico) a 0,1\%]) (AOAC, 1997), acidez titulável ( $\mathrm{g}$ de ácido cítrico/100 mL de suco, determinada por titulação com solução de $\mathrm{NaOH}$ 0,1 molL $^{-1}$ ) e produção de $\mathrm{CO}_{2}$ (determinada semanalmente, logo após a coleta no campo). As determinações da produção de $\mathrm{CO}_{2}$ foram feitas por cromatografia gasosa, utilizando-se cromatógrafo a gás Gow Mac série 550, equipado com detector de condutividade térmica e coluna de alumínio preenchida com Porapak Q (Alves, 2010).

$\mathrm{O}$ delineamento experimental foi o inteiramente casualizado, com os tratamentos correspondendo aos dias de amostragem e quatro repetições, sendo cinco frutos por unidade experimental. As curvas de crescimento foram determinadas por análise de regressão.

Para a análise dos dados, utilizou-se o Sistema de Análises Estatísticas e Genéticas da Universidade Federal de Viçosa, versão 9.1 (SAEG, 2007). Esses dados foram submetidos às análises de regressão linear e não linear, sendo escolhido o modelo com melhor grau de ajuste (porcentagem da variância explicada, $\mathrm{R}^{2}$ ) e melhor representação do fenômeno em estudo.

As curvas de ajuste sigmoidal foram ajustadas conforme o modelo:

$$
\mathrm{Y}_{i}=\frac{\mathrm{a}}{1+\mathrm{EXP}(\mathrm{b}-\mathrm{cx})}+e_{i}
$$

em que: a, b, c = parâmetros de ajuste; e $e_{i}=$ erro.

Os pontos de inflexão corresponderam ao momento em que ocorreram as taxas máximas de acúmulo nos frutos. Os pontos críticos mínimo (PCmín. ) e máximo (PCmáx.) foram determinados por cálculos matemáticos:

$$
\mathrm{PC}_{\text {min }}=\frac{\mathrm{b}-2}{\mathrm{c}} \quad \mathrm{PC}_{\text {max }}=\frac{\mathrm{b}+2}{\mathrm{c}}
$$

O PCmín. indica o momento na curva de acúmulo em que se iniciam ganhos expressivos nas matérias fresca e seca e nas dimensões dos frutos. Já o PCmáx. indica o momento em que o acúmulo dos componentes começa a se estabilizar (Alves, 2010).

\section{RESULTADOS E DISCUSSÃO}

Durante o surto principal de florescimento foram marcadas 5.639 flores. Desse total, 1.794 desenvolveram frutos, resultando num percentual de vingamento de $30,8 \%$. Esse dado é semelhante ao encontrado por Veras (1997), de 30,4\%, trabalhando com polinização natural em maracujá doce, nas condições de Cerrado de Brasília, DF. 
O período de formação do fruto do maracujazeiro doce em Viçosa teve duração de 91 dias, sendo mais curto que o período de 102 dias observado por Vasconcellos et al. (1993) em Botucatu, SP (890 m de altitude), que registraram, durante seu experimento, umidade relativa média do ar de 67,2\%, 304,6 mm de precipitação pluvial e temperatura média de $17,5^{\circ} \mathrm{C}$. É provável que as condições ambiente de Viçosa, como menor altitude (651 m), temperatura média mais alta $\left(18,0^{\circ} \mathrm{C}\right)$ e precipitação pluvial mais baixa (173,4 mm) durante o período experimental, tenham contribuído para o menor período de formação dos frutos.

Os acréscimos em comprimento e em diâmetro dos frutos foram muito semelhantes. Como o dia zero das avaliações foi definido como o dia da abertura floral, as medidas do diâmetro e do comprimento foram tomadas do ovário, órgão que dá origem ao fruto, caso este seja fecundado. As medidas do comprimento ajustaram-se ao modelo sigmoidal simples em resposta à variação do tempo (Figura 1A). A taxa de crescimento máxima do comprimento ocorreu aos 12,44 daa, com ganho diário de 2,61 mm. O ponto crítico máximo ocorreu aos 27,41 daa, indicando que a partir desse dia o comprimento começou a estabilizar.

Na Figura 1B, verifica-se que a taxa de crescimento máxima do diâmetro ocorreu aos 13,94 daa, com ganho diário de 2,40 mm, e o ponto crítico máximo ocorreu aos 27,99 daa. As medidas ajustaram-se ao modelo sigmoidal simples em resposta à variação do tempo.

As medidas do volume ajustaram-se ao modelo sigmoidal simples em resposta à variação do tempo, com ponto crítico mínimo aos 12,10 daa e máximo aos 34,20 daa (Figura 1C). A taxa de crescimento máxima do volume ocorreu aos 24,04 daa, com ganho de 7,97 $\mathrm{cm}^{3} / \mathrm{dia}$. $\mathrm{O}$ aumento do volume do fruto até os 14 daa foi mais lento diante do crescimento do comprimento e do diâmetro, quando ganhos expressivos nas dimensões correspondem a pequenos acréscimos no volume. A partir dos 14 daa, a situação inverte-se e pequenos ganhos em comprimento e diâmetro correspondem a grandes ganhos em volume (Figura 1C).

As medidas de massa da matéria fresca do fruto (Figura 1D), da polpa (Figura 1E) e do pericarpo (Figura 1F) ajustaram-se ao modelo sigmoidal simples em resposta à variação do tempo. Para a massa da matéria fresca do fruto (massa total), o ponto crítico mínimo ocorreu aos 10,30 daa, indicando início dos ganhos expressivos na massa do fruto (Figura 1D). A taxa de crescimento máxima aconteceu aos 23,28 daa, com ganho diário de 6,09 g/ dia. O ponto crítico máximo aconteceu aos 36,32 daa, indicando que a partir desse dia a massa do fruto começou a se estabilizar, o que corresponde a $87,69 \%$ do acúmulo máximo.
Para a massa da matéria fresca da polpa, o ponto crítico mínimo ocorreu aos 29,70 daa e a taxa de crescimento máxima aos 44,83 daa, com ganho diário de 2,45 g/dia (Figura 1E). O ponto crítico máximo aconteceu aos 60,09 daa, o que corresponde a $88,11 \%$ do acúmulo máximo. $\mathrm{O}$ acúmulo de massa da matéria fresca da polpa (Figura 1E) só começou a ser expressivo quando o desenvolvimento do comprimento (Figura 1A), do diâmetro (Figura 1B), do volume (Figura 1C) e da massa da matéria fresca do pericarpo (Figura 1F) ultrapassaram os pontos críticos máximos.

Para a massa da matéria fresca do pericarpo, a fase de crescimento acelerado estendeu de 7,99 daa aos 30,60 daa, quando o fruto atingiu 87,85\% do acúmulo máximo (Figura $1 \mathrm{~F})$. A taxa de crescimento máximo ocorreu aos 19,84 daa, com ganho diário de 5,63 g/dia. É possível verificar que, durante os primeiros 30 daa, o ganho de massa no fruto foi preferencialmente para a formação do pericarpo (Figuras 2A e 2B), e a diminuição de sua espessura ocorreu concomitantemente com o desenvolvimento e ganho de massa da matéria fresca pelo suco e pelas sementes (Figura 2E). Houve variação percentual das massas do pericarpo, da polpa e semente ao longo do desenvolvimento do fruto (Figura 2F). No início do desenvolvimento, o pericarpo correspondeu a $100 \%$ do fruto, pois nesse ponto ainda não houve a formação de sementes nem de polpa. Ao longo do tempo, houve declínio do percentual de massa do pericarpo e aumento no percentual de polpa e semente, tendo o fruto, no último dia de análise, a proporção de $74,10 \%$ de pericarpo, $24,46 \%$ de polpa e $3,14 \%$ de sementes.

O comprimento e diâmetro guardam entre si relação linear (Figura 2A), apresentando coeficiente angular de 0,92 entre os dois parâmetros. No início do desenvolvimento (zero daa), o fruto apresentava-se mais alongado, com o comprimento $80,4 \%$ maior que seu diâmetro. Essa proporção foi reduzindo gradativamente até 42 daa, quando o comprimento apresentou-se $17,1 \%$ maior que o diâmetro, e permaneceu nessa proporção até 91 daa, conferindo aos frutos formato ligeiramente oblongo, em vez de piriforme, típico de vários genótipos de maracujá doce (Manica et al., 2005).

A espessura do pericarpo aumentou rapidamente da abertura floral até 34,94 daa, quando atingiu seu máximo de 14,38 mm (Figura 2B). Esse valor é 649,4\% maior que o inicial, registrado no dia da abertura floral. Em termos percentuais, o fruto apresentou sua maior proporção de pericarpo aos 6,38 daa, quando a espessura dele representava 79,01\% do diâmetro do fruto. Com o desenvolvimento do fruto, a proporção diminuiu gradativamente, chegando a 29,98\% do diâmetro aos 91 daa, último dia de avaliação. A redução da espessura do pericarpo e, consequentemente, o aumento do diâmetro da cavidade 
ovariana podem estar relacionados com a destruição progressiva dos tecidos da parede interna do pericarpo em favor do desenvolvimento das sementes e do arilo (Gamarra Rojas \& Medina, 1995). A partir do momento em que o fruto atinge seu comprimento (27,41 daa), diâmetro (27,99 daa) e volume (34,20 daa) máximos, a espessura do pericarpo começa a diminuir, cedendo espaço ao ganho de massa da matéria fresca da polpa (Figura 1E).

A evolução do ângulo hue ( $\left.{ }^{\circ} \mathrm{h}\right)$, que permite visualização precisa da mudança da cor na casca dos frutos (Silva et al., 2009), ajustou-se ao modelo quadrático (Figura 2C). Os frutos, aos 7 daa, apresentaram tonalidade verde-clara $\left(111,02^{\circ} \mathrm{h}\right)$ e cor verde mais intensa aos 35,26 daa $(126,00$ ${ }^{\circ}$ h). Nos dias seguintes, houve acentuado declínio do ângulo hue devido à maturação do fruto, quando a coloração verde gradualmente se extinguiu, resultado da degradação da clorofila presente no pericarpo e da síntese e, ou, da manifestação dos pigmentos carotenoides.

Verificou-se que o acúmulo de massa da matéria seca pelo pericarpo foi crescente até 65,28 daa, quando atingiu
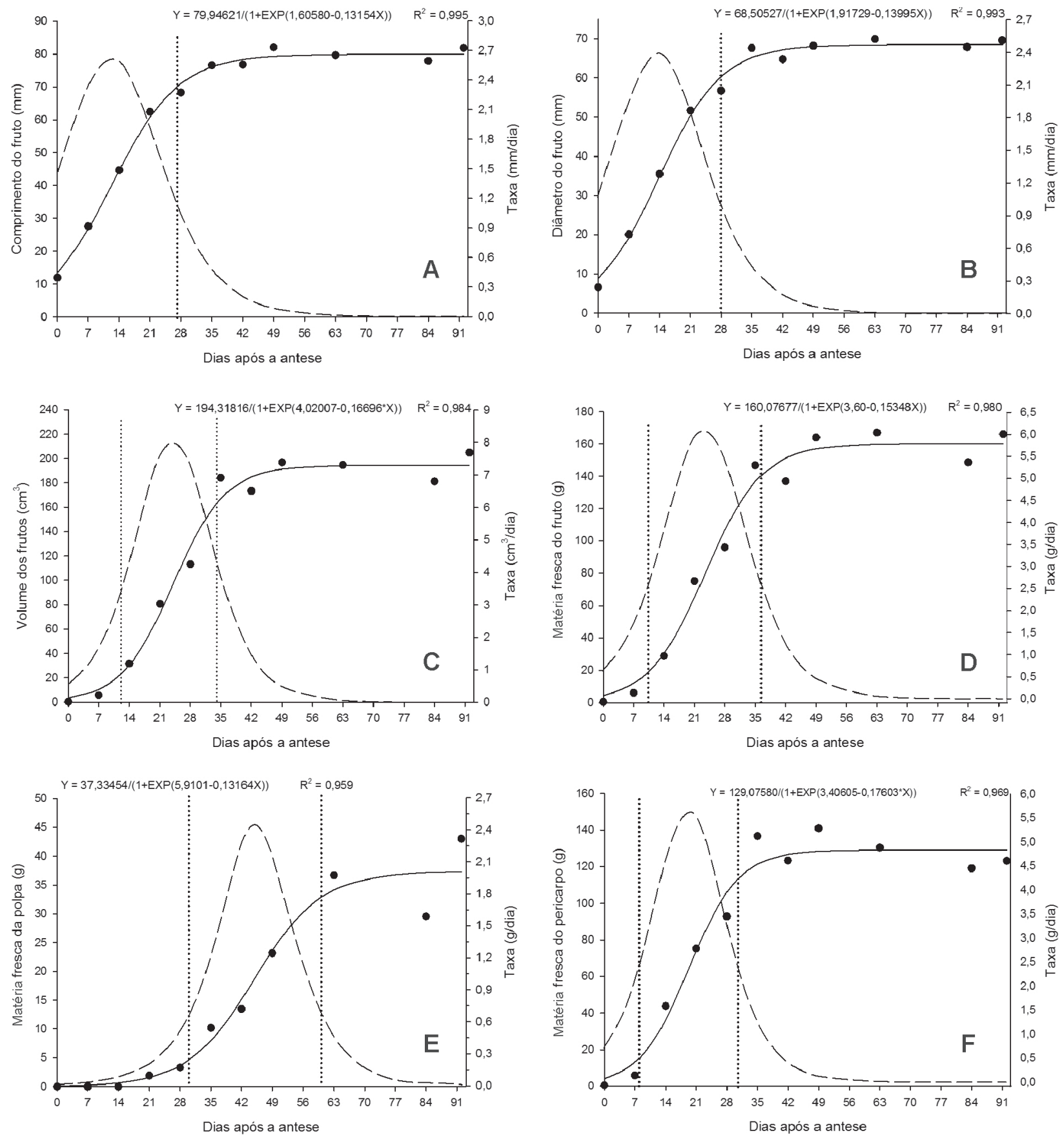

Figura 1. Valores observados e estimados do comprimento (A), diâmetro (B), volume (C), massa da matéria fresca do fruto (D), massa da matéria fresca da polpa (E) e massa da matéria fresca do pericarpo (F) durante o desenvolvimento do maracujá doce, em função do tempo. As linhas pontilhadas indicam os pontos críticos mínimos e máximos e a tracejada, a derivada primeira da curva de crescimento. 

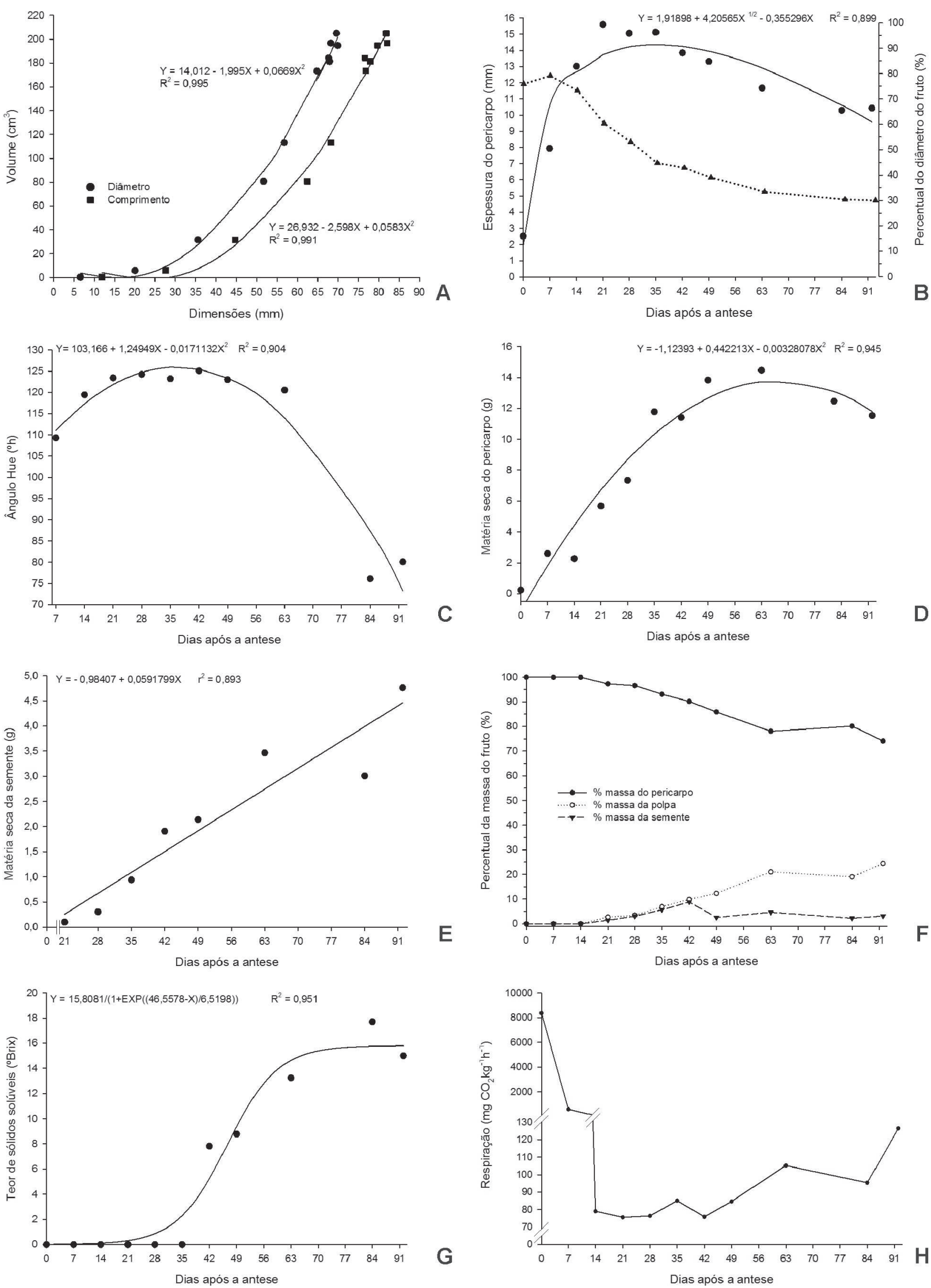

Figura 2. Valores observados e estimados de volume do fruto (A), espessura do pericarpo (B) e ângulo Hue (C), massa da matéria seca do pericarpo (D) e massa da matéria seca da semente (E), percentual das massas da matéria fresca do pericarpo, da polpa e da semente (F), teor de sólidos solúveis $(\mathrm{G})$ do maracujá doce em função do tempo. Valores observados da produção de $\mathrm{CO}_{2}\left(\mathrm{mg} \mathrm{CO}_{2} \mathrm{~kg}^{-1} \mathrm{~h}^{-1}\right)$ durante o desenvolvimento do maracujá doce $(\mathrm{H})$. 
13,74 g (Figura 2D). Isso indica que houve migração de massa fresca para a polpa, principalmente água. Após 65,28 daa, a massa da matéria seca do pericarpo tendeu a decrescer. É possível que a redução se deva à translocação de assimilados da casca para a polpa, já que esta se tornou dreno forte após a estabilização do crescimento do pericarpo.

O teor de sólidos solúveis da polpa ajustou-se ao modelo sigmoidal simples, com ganhos até o último dia de avaliação (Figura 2G). Tal resposta foi semelhante ao observado por Vasconcellos et al. (1993) e diferente do encontrado por Araújo et al. (1974) em maracujá-amarelo, que apresenta decréscimo no teor de sólidos solúveis em períodos próximos à colheita.

Dos $63^{\circ}$ aos $91^{\circ}$ daa, o teor de vitamina $\mathrm{C}$ foi decrescente no maracujá doce (de 57,0 a 40,0 mg ácido ascórbico/ $100 \mathrm{~g}$ suco), bem como a acidez titulável (2,3 a 1,5\% ácido cítrico), fato comum nos frutos em estágio final de amadurecimento e senescência, quando os ácidos orgânicos começam a ser utilizados como substrato para o processo de respiração (Chitarra \& Chitarra, 2005). Apesar disso, o teor de vitamina $\mathrm{C}$ encontrado foi superior ao observado por Veras et al. (2000) em maracujá doce $(26,49 \mathrm{mg} / 100 \mathrm{~g})$ e maracujá-amarelo $(30,77 \mathrm{mg} / 100 \mathrm{~g})$, equiparando-se aos encontrados em frutos cítricos apirênicos (Santos et al., 2010) e em lichia (Silva et al, 2010).

De modo geral, a taxa de respiração é indicativa da rapidez com que as mudanças de composição ocorrem (Chitarra \& Chitarra, 2005). A atividade metabólica nos primeiros 14 dias de desenvolvimento do maracujá doce foi muito intensa (Figura 2H). Em geral, os tecidos jovens que apresentam células em crescimento ativo possuem taxas de respiração mais elevadas que os tecidos com células mais velhas ou maduras (Chitarra \& Chitarra, 2005), fato que não tem relação com o padrão climatérico ou não climatérico do fruto (Taiz \& Zeiger, 2008).

A taxa de produção de $\mathrm{CO}_{2}$ decresceu de $8.363,12 \mathrm{mg}$ $\mathrm{CO}_{2} \mathrm{~kg}^{-1} \mathrm{~h}^{-1}$ em 0 daa para 608,25 mg CO $\mathrm{kg}^{-1} \mathrm{~h}^{-1}$ aos 7 daa. Essa queda brusca na atividade respiratória deve-se ao fato de o fruto estar crescendo rapidamente no início de seu desenvolvimento. De 7 daa a 14 daa, a produção de $\mathrm{CO}_{2}$ continuou em queda, porém mais suave, passando de 608,25 mg CO $\mathrm{kg}^{-1} \mathrm{~h}^{-1}$ para 79,03 mg CO $\mathrm{kg}^{-1} \mathrm{~h}^{-1}$. Dos 14 aos 49 daa, houve estabilização na produção de $\mathrm{CO}_{2}$, com média de 79,41 mg CO $\mathrm{kg}^{-1} \mathrm{~h}^{-1}$; e dos 49 aos 63 daa ocorreu aumento do $\mathrm{CO}_{2}$, caracterizado como ascensão climatérica, até atingir o pico aos 63 daa, com produção de 105,18 mg $\mathrm{CO}_{2} \mathrm{~kg}^{-1} \mathrm{~h}^{-1}$. Pode-se observar que eventos importantes aconteceram simultaneamente no pico climatérico, como o ponto crítico máximo para a massa da matéria fresca da polpa, o valor máximo atingido para a massa da matéria seca do pericarpo e o início da estabilização do teor de sólidos solúveis.
Durante o desenvolvimento do maracujá doce foram identificadas três fases, delimitadas pelos PCmín. e PCmáx. das equações de ajuste das características físicas referentes ao fruto inteiro. Segundo Chitarra \& Chitarra (2005), nesse modelo a primeira fase é predominantemente de intensa divisão celular, a segunda de expansão rápida e a terceira de maturação. Também pode-se notar que os PCmín. e PCmáx. variaram de acordo com a característica avaliada. Portanto, embora seja possível estabelecer as fases do desenvolvimento de cada uma das características, optou-se por utilizar suas médias para a delimitação do intervalo de tempo de cada fase.

A primeira fase do desenvolvimento do fruto variou de 0 daa (antese) a 12,10 daa, caracterizada pela alta taxa respiratória (Figura $2 \mathrm{H}$ ), provavelmente devido à intensa multiplicação celular (Taiz \& Zeiger, 2008), fato verificado pelo crescimento acelerado da espessura do pericarpo (Figura 2B). Ainda nesta fase, o fruto apresenta pericarpo com coloração verde-clara (Figura 2C) e os incrementos no comprimento, diâmetro, volume e na massa do fruto são muito pequenos. Consequentemente, sementes e polpa praticamente ainda não começaram a se desenvolver.

A segunda fase do desenvolvimento estendeu-se de 4,70 daa até 28,94 daa (média). Nesta fase, registraram-se as taxas máximas de incremento das dimensões e da massa do fruto, a taxa respiratória manteve-se estável (dos 14 aos 49 daa) e o pericarpo desenvolveu a cor verde-intensa $\left(126,00^{\circ} \mathrm{h}\right.$ ) (Figura 2C). De acordo com Taiz \& Zeiger (2008), durante o alongamento celular os polímeros de parede são constantemente sintetizados, ao mesmo tempo em que a parede pré-existente se expande. Durante essa fase, houve grande incremento no comprimento, diâmetro, volume e na espessura do pericarpo e acúmulo de massa da matéria fresca, resultante, principalmente, de grande expansão celular e acúmulo de água no fruto. Nesse período houve formação de sementes a partir de 21 daa, e a polpa começou a se desenvolver.

A terceira e última fase estendeu-se de 28,94 daa até 91,00 daa, último dia de avaliação. Nessa fase, houve tendência à estabilização nas dimensões e no acúmulo de massa da matéria fresca, salvo a massa da matéria fresca da polpa, que persistiu com ganhos expressivos até 74,10 daa. Foram observados nesse período a ascensão climatérica (de 49 daa a 63 daa) e o climatério (63 daa), com pico de produção de $\mathrm{CO}_{2}$ de $105,18 \mathrm{mg} \mathrm{CO}_{2} \mathrm{~kg}^{-}$ ${ }^{1} h^{-1}$. Essa é a fase de amadurecimento do fruto, quando há aumento no teor de sólidos solúveis na polpa. Paralelamente, ocorre queda da acidez titulável e vitamina $\mathrm{C}$. No entanto, o pericarpo gradativamente desenvolve coloração amarelo-palha (Figura 2C), característica da espécie. Nessa terceira fase, observou-se o desenvolvimento de aroma e sabor característicos de fruto completamente maduro para consumo. 


\section{CONCLUSÕES}

O período de formação do fruto do maracujazeiro doce em Viçosa estendeu-se por 91 dias.

O padrão de desenvolvimento ajustou-se ao modelo sigmoidal simples, com três estágios de crescimento: até 4,70 daa, de 4,70 a 28,94 daa e de 28,94 a 91 daa.

O climatérico respiratório dos frutos foi atingido aos 63 dias após a antese.

\section{REFERÊNCIAS}

Alves RR (2010) Desenvolvimento do fruto de maracujazeiro doce (Passiflora alata Curtis) em Viçosa, Minas Gerais. Dissertação de Mestrado. Universidade Federal de Viçosa, Viçosa. 42p.

AOAC - Official methods of analysis of the Association of Official Analytical Chemists International (1997). 16th ed. Washington: AOAC, $2: 10-37 ; 2-42 ; 344 ; 16-45$.

Anjos ECT, Cavalcante UMT, Santos VF \& Maia LC (2005) Produção de mudas de maracujazeiro doce micorrizadas em solo desinfestado e adubado com fósforo. Pesquisa Agropecuária Brasileira, 40:345-351.

Araújo CM, Gava AJ, Robbs PG, Neves JF \& Maia PBC (1974) Características industriais do maracujá (Passiflora edulis f. flavicarpa) e maturação do fruto. Pesquisa Agropecuária Brasileira, 9:65-71.

Chitarra MLF \& Chitarra AB (2005) Pós-colheita de frutos e hortaliças - Fisiologia e manuseio. $2^{\mathrm{a}}$ ed. Lavras, UFLA. 785p.

Gamarra Rojas G \& Medina VM (1995) Variações físico-químicas do maracujá ácido em relação à pigmentação da planta. Revista Brasileira de Fruticultura, 17:103-110.

Manica I, Brancher A, Sanzonowics C, Icuma IM, Aguiar JLP, Azevedo JA, Vasconcellos MAS, Junqueira NTV Maracujá-doce: tecnologia de produção, pós-colheita, mercado. Porto Alegre: Cinco Continentes, 2005. 224p.
SAEG (2007) Sistema para análises estatísticas versão 9.1. Universidade Federal de Viçosa. Viçosa, Fundação Arthur Bernardes.

Salomão LCC, Siqueira DL \& Pereira MOEC (2006) Desenvolvimento do fruto da lichieira (Litchi chinensis Sonn.) 'Bengal'. Revista Brasileira de Fruticultura, 28:11-13.

Santos D, Matarazzo PHM, Silva DFP, Siqueira DL, Santos DCM \& Lucena CC (2010) Caracterização de frutos cítricos apirênicos produzidos em Viçosa - Minas Gerais. Revista Ceres, 57:393400 .

Silva DFP, Cabrini EC, Salomão LCC \& Alves RR (2010) Uso do ácido ascórbico no controle do escurecimento do pericarpo de lichia. Revista Brasileira de Fruticultura, 32:618-627.

Silva DFP, Salomão LCC, Siqueira DL, Cecon PR \& Rocha A (2009) Potassium permanganate effects in postharvest conservation of the papaya cultivar Sunrise Golden. Pesquisa Agropecuária Brasileira, 44:669-675.

Taiz L \& Zeiger E (2008) Fisiologia vegetal. 4ª ed. Porto Alegre, Artmed. 820p.

Vasconcellos MAS, Cereda E, Andrade JMB \& Brandão Filho JUT (1993) Desenvolvimento de frutos de maracujazeiro doce (Passiflora alata Dryand), nas condições de Botucatu-SP. Revista Brasileira de Fruticultura, 15:153-158.

Veras MCM (1997) Fenologia, produção e caracterização físicoquímica dos frutos de maracujazeiro ácido (Passiflora edulis $\mathrm{f}$. flavicarpa Deg.) e doce (Passiflora alata Dryand) nas condições de Cerrado de Brasília-DF. Dissertação de Mestrado. Universidade Federal de Lavras, Lavras. 105p.

Veras MCM, Pinto ACQ \& Meneses JB (2000) Influência da época de produção e dos estádios de maturação nos maracujá doce e ácido nas condições de cerrado. Pesquisa Agropecuária Brasileira, 35:959-966. 